\title{
Nomophobia an Emerging Fear: An Experimental Exploration among University Students
}

\author{
Iram Batool ${ }^{1}$ \\ Bahauddin Zakariya University Multan \\ and \\ Ayesha Zahid ${ }^{2}$ \\ Institute of Southern Punjab, Multan
}

Modern communication technologies have become a very essential part of our lives, especially smartphones (Salehan \& Negahban, 2013). Present study explored the effects of fear of separation from the smartphone on university students. The sample comprised of three hundred students of Bahauddin Zakariya University Multan with age range of 18-30 years. The purpose of the present study was to explore the existence of nomophobia among smartphone users. Furthermore, it aimed to investigate whether smartphone separation causes anxiety. An experimental research design was used and participants were randomly assigned to two conditions. Two measures were used in the study: The State-Trait Anxiety Inventory (STAI) developed by Spielberger, (1983), and a nomophobia questionnaire (NMP-Q) developed by Yildirim (2015). Results revealed that $68 \%$ of the students experienced moderate level of nomophobia and the level of anxiety gradually increased with increase in duration of the separation from the phone. One-way analysis of variance found significant difference on different levels of anxiety in experimental group I and experimental group II separately. No significant gender differences were found for state anxiety and nomophobia. It is concluded from the findings of the study that excessive use and dependence on smartphones can cause anxiety and feeling of restlessness in the absence of the smartphone.

Keywords: nomophobia, state anxiety, experimental group, mobile phones, anxiety.

\footnotetext{
${ }^{1}$ Assistant Professor, Department of Applied Psychology, Bahauddin Zakariya University Multan, Pakistan

${ }^{2}$ Institute of Southern Punjab, Multan, Pakistan

ISSN 2415-6779 EISSN 2518-4474

https://doi.org/10.32879/picp.2019.5.1.67

www.pjpbsicp.com
} 
Information and modern communication technologies (ICT) have captured our lives (Salehan \& Negahban, 2013). Current era is considered as a mobile phone era where there is an expansion of lowpriced mobile devices. People are adopting mobile ICTs very quickly and vigorously (Oulasvirta, Rattenbury, Ma, \& Raita, 2012). Smartphones are considered as the latest advancement of mobile ICTs in this modern mobile age (Oulasvirta, Rattenbury, Ma, \& Raita, 2012) and people are getting addict to their use.But the excessive use of smartphones can cause many physical, psychological and psychosocial problems among smart phone users. Insomnia, poor sleep quality excessive day time sleepiness (Khan, 2008) personal stress, insecurity, low self-confidence and frequent mood changes, all these problems are due to excessive cell phone use (Sansone, \& Sansone, 2013).

Due to this new form of addiction that is smartphone addiction, both individual and society are neglecting work and study (Bianchi, \& Phillips, 2005). Similarly people use this technological device in order to avoid social interactions (Billieux, Van der Linden, \& Rochat, 2008) or use them compulsively as a protective or defensive shell. In addition to all these problems an emerging problem related to mobile phone use is nomophobia. Nomophobia is defined as "Fear of being away from mobile phone contact" (Yildirim, 2014). Nomophobia is derived from three words no-mo-phobia meaning no-mobile-phone phobia and was first originated during a study investigated on mobile phone users who suffered from anxiety when they lose contact with their cell phone, piloted by the UK Post Office in 2008. A study conducted by King et al., (2014) defined nomophobia as Anxiety arising from not being able to communicate through internet or mobile phone (MP) in the modern world".

Nomophobia consists of a cluster of symptoms or behaviors that are related to mobile phone use. Another phenomenon which may lead toward nomophobia is fear of missing out (FoMO) that is designated by the desire to develop a continuous link with what other people are doing (Przybylski, Murayama, DeHaan, \& Gladwell, 2013). If people do not check their phones frequently they become overly concerned that they might miss a chance of any social event, or any other event which make them feel good (Walsh, White, \& Young, 2009). Dopamine is triggered. When a person hears the sound of phone ringing, receives a notification of a message or a text message from someone they like and an email with some happy news slightly increases the level of dopamine (Tanaka \& Terry-Cobo, 2008).

People who suffer from nomophobia have following characteristics; they avoid any social communication, other than through 
their mobile phone, they have one or more mobile phones with internet access, they consider their cell phone as a protective layer, always keep their charger with themselves, avoid places or situations in which mobile phone use is restricted which then leads to feelings of stress and anxiety, always keep their cell phones switched on, they have few face to face social interactions and prefer to communicate through new technologies and check their phones again and again to check if they received a call or a message from someone (Bragazzi \& Puenete, 2014).

\section{Anxiety}

Of all human emotions, anxiety is considered as one of the common and ubiquitous emotion (Sarason \& Sarason, 1990). Anxiety refers to a person's psychological state in which feelings of worry and uncertainty are activated by vague conditions. It is very difficult for the individual to cope with the ambiguous danger because the origin and nature of threat is unclear to the individual and thus he/she does not know how to react in this situation. Sometimes anxiety is thought to be future oriented because the person foretells different circumstances of being unemployed, due to this the person show apprehension and fear. Both physical and mental symptoms of anxiety can be experienced by an individual. Some common physical changes that (occur in response to anxiety are fight or flight response, gastric disturbance, pounding heart and perspiration. Other feelings while experiencing anxiety are worries, nervousness, intrusive thoughts and tension (Zeidner, \& Matthews, 2010).

\section{State-Trait Anxiety}

Stable tendency across many situations such as to experience, to attend and to report negative emotions like worries, fears, and anxiety refers to trait anxiety. Trait anxiety is the part of the personality dimension of emotional stability versus neuroticism (Gidron, 2013). Body symptoms are also manifested by trait anxiety. A stable perception of certain environmental stimuli such as events, others and statements are characterized by people having trait anxiety as threatening. State anxiety is also often experienced and expressed by anxious people in situations when people do not show threatening responses. This tendency is supposed to reflect a cognitive-perceptual bias. At the cognitive level, a person has a distorted negative interpretation related to everything and this strengthens anxious responses just like generalized anxiety disorder. At the perceptual level people's focus of attention is only on the threatening responses. At the memory level, they only recall threatening memories (Gidron, 2013). 
State anxiety (Situational anxiety) can be defined in terms of Specific Phobia by DSM-5, APA (2013) as diagnosis assigned to individuals who suffer from intense fear or anxiety when exposed to specific objects or situations. A type of anxiety disorder, specific phobias may present in response to a range of stimuli, from animals to medical procedures. when a person is faced with a threatening situation autonomic nervous system temporarily induces fear, worry and discomfort such as what are the feelings of a person when a threatening situation is perceived by him for example if a child is confronted by a large, strange animal and responds anxious to this. In the same way when a person gets on a flight for the first time, s/he becomes anxious (Spielberger \& Sydeman, 1994).

There is a noticeable increase in the smart phone usage and it is disturbing the life patterns of people. As the use of smart phone and cyber loafing increases, the person becomes more vulnerable to develop smartphone addiction and self-regulation negatively correlated with smartphone addiction (Gökçearslan, Mumcu, Haşlaman, \& Çevik, 2016). Existing literature explained that people experience this type of anxiety or fear when in reality their cell phone was apart from them. In one study the pattern of mobile phone usage and prevalence of nomophobia were checked and the results indicates that $73 \%$ of students were nomophobics. $21 \%$ of nomophobics experienced anxiety $83 \%$ of students experienced panic attacks when their mobile phones were misplaced (Sharma, Sharma, Sharma, \& Wavare, 2015). Many already conducted researches only ask question about their feelings if they would separate from their cell phone but uniqueness of this study is that it will measure immediate responses in real situations.

The purpose of this study was to explore the existence of the fear related to their cell phones; furthermore, it also aimed at exploring it through the real separation of the cell phone. For this purpose, an experiment was designed. The idea for this research was taken from a study in which researcher examined the anxiety in American students when their mobile phones were separated from them (Cheever, Rosen, Carrier \& Chavez, 2014). The replication of similar methodology in an eastern culture with some changes to examine anxiety at three stages and these stages told either there was an increase in anxiety or not as the time passed when students have no smart phone with them. 


\section{Objectives of the study:}

1. To find the level of nomophobia and anxiety among university students, in response to separation effect when smartphones were completely taken away (Experimental condition I).

2. To find the difference of nomophobia and anxiety among university students, in response to separation effect when smartphones were only switched off (Experimental condition II).

3. To study the effect of increase in time duration of removing or switching off the mobile phones in the above two conditions among university students.

4. To investigate the difference of nomophobia and anxiety among mobile phone users when the smartphone was completely taken away comparing with the those mobile phone users whose smartphones were only switched off.

\section{Hypotheses:}

1. Completely taking away the mobile phones will cause more anxiety as compared to switching off the mobile phones among mobile phone users.

2. Increasing time duration of removing or switching off the mobile phones of mobile phone users will result in rise in the level of anxiety and nomophobia.

\section{Method}

\section{Participants}

Participants $(\mathrm{N}=300)$ were recruited from the sociology and psychology department of Bahauddin Zakariya University Multan. Participants ranged in age from 18 to 30 years with an average age of 20.29 ( $S D=3.046)$ where mean age for females was $20.29(\mathrm{SD}=3.05)$ and average age for males was $20.27(\mathrm{SD}=3.07)$. Mean age in experimental group I was $20(\mathrm{SD}=1.35)$ and mean age in experimental group II was 20.58 ( $\mathrm{SD}=4.07)$. The age distribution generally represented the university students. Gender was distributed with males ( $\mathrm{n}=66), 22 \%$ and females $(\mathrm{n}=234), 78 \%$ of the sample. Where $(\mathrm{n}=131)$ participants were from M.Sc., $43.67 \%$ and $(n=169)$ participants were from BS, $56.33 \%$.

\section{Measures}

State-Trait Anxiety Inventory: State-Trait Anxiety inventory was invented by Spielberger in 1983 and based on a self-reported 40 item 
lickert scale. This inventory was developed for measuring levels of state anxiety and trait anxiety. In the present study one subscale of state anxiety was included for measuring state anxiety. This inventory has a very good reliability and validity (Gros, Antony, Simms and McCabe, (2007), Alpha reliability coefficient ranging from 0.86 for high school students to 0.95 for military recruits (Spielberger 1983)

Nomophobia Questionnaire: This questionnaire was developed by Caglar Yildirim in 2015 at Iowa State University in order to diagnose the psychological condition of people who suffer from nomophobia NMPQ was used. Students were asked to respond to the items on a Likert scale ranging from 1 (Strongly disagree) to 7 (Strongly agree). Total scores were then added. The greater the score the greater the severity of nomophobia. The reliability for the NMP-Q is Cronbach's alpha $=.94$, which is very good (Yildirim, 2015).For the current sample the reliability is 0.86 .

\section{Procedure}

The study was conducted at the Department of Applied Psychology and the Department of Sociology at Bahauddin Zakariya University Multan. Students who participated in the study were enrolled in different programs. True purpose of the research was not told to the participants. The debriefing statement was issued at the end of the experiment. The study took place during regular classes. Directions and instructions were given to participants before the experiment. All the scales were measured before and after the experimental condition. The detailed procedure is given in flowchart below.

\section{Experimental Condition I}

The description of stages in experimental groups is discussed below.

Stage 1: At stage 1 the State Anxiety Inventory in order to check their present feelings, when their cell phones were with them. After the administration researcher gave participants envelops and instructed them to write their names, roll numbers on envelop, turn off their cell phones and put them in envelops and seal envelops with the tapes for security and ethical purpose. Then envelops were submitted to the researcher. The cell phones were then taken out of the class by the researcher.

Stage 2: At stage 2 after an hour researcher again administered State Anxiety inventory on participants in order to check that without their cell phones either their anxiety had increased at stage 2 or not. 
Stage 3: At the third stage after two hours researcher again administered the State Anxiety inventory in order to check whether the separation effect increases with increase in time duration of separating the mobile phones. At this stage researcher also administered nomophobia questionnaire, in order to check the intensity of fear without their cell phones. After all the three stages researcher returned back the cell phones to the participants.

\section{Experimental Condition II}

The description of all the three stages for experimental condition II is discussed below.

Stage 1: At stage 1 researcher administered State anxiety inventory to check the present feelings of the participants. After the initial administration of the state anxiety inventory, participants were requested to not to use their cell phone during the experiment and turn their cell phones off.

Stage 2: At stage 2 after two hour the researcher again administered State anxiety inventory to check whether there is an increase in their feelings of anxiety or not.

Stage 3: At stage 3 after two hours State anxiety inventory was administered again now with the nomophobia questionnaire to check if there is an increase in fear and anxiety of participants while their cell phones were off but with them. After the experiment participants were allowed to turn on their cell phones.

\section{Flow Chart}

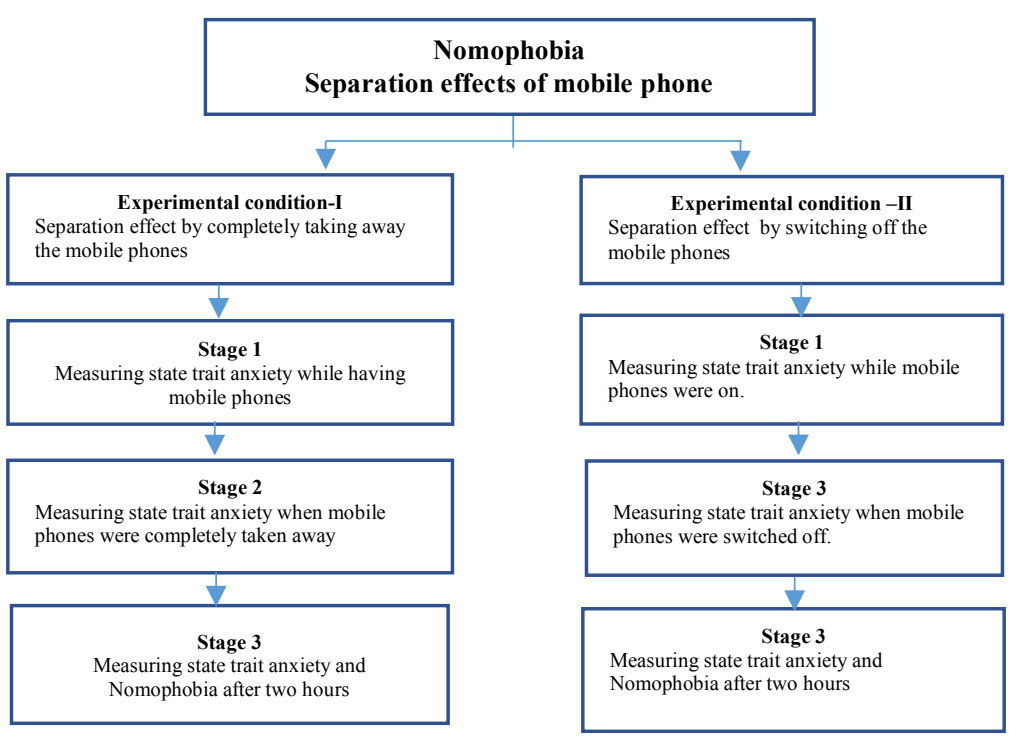




\section{Results}

The results were analyzed by using SPSS. The results were presented by using descriptive statistics, by using one way and two way analysis of variance (ANOVA) between and within groups separately for experimental group I and experimental group II.

Table 1

Alpha Reliability Coefficient of the Scales

\begin{tabular}{lcc}
\hline Scale & No of items & Cronbach's Alpha \\
\hline Nomophobia (NMP-Q) & 20 & 0.86 \\
State anxiety stage 1 & 20 & 0.84 \\
State anxiety stage 2 & 20 & 0.82 \\
State anxiety stage 3 & 20 & 0.89 \\
\hline
\end{tabular}

Table 1 shows the alpha reliability of the scales of the study. The results reveals high alpha reliability coefficient for all the scales of the study

Table 2

Descriptive Statistics of the Study

\begin{tabular}{llcc}
\hline & & Frequency & Percentage \\
\hline \multirow{2}{*}{ Variables } & Condition I & 150 & $50 \%$ \\
& Condition II & 150 & $50 \%$ \\
\hline \multirow{2}{*}{ Age } & $\leq 25$ years & 284 & $94.67 \%$ \\
& $\geq 26-30$ years & 16 & $5.33 \%$ \\
\hline \multirow{2}{*}{ Gender } & Female & 234 & $78 \%$ \\
& Male & 66 & $22 \%$ \\
\hline \multirow{2}{*}{ Education } & M.Sc & 131 & $43.67 \%$ \\
& BS & 169 & $56.33 \%$ \\
\hline & Total & 300 & $100.0 \%$ \\
\hline
\end{tabular}

Table 2 shows that the frequency of group is described and expressed in terms of percentage. Frequency table shows (150) 50\% respondents are belonging to experimental condition I and (150) $50 \%$ respondents are belonging to experimental condition II. Frequency table show (284) $94.67 \%$ respondents are under 25 years of age, (16) $5.33 \%$ respondents are between 25-30 years of age. Frequency table show (150) $50 \%$ respondents are male and (150) 50\% respondents are female. Frequency table show (131) $43.67 \%$ respondents are of M.Sc and (169) $56.33 \%$ respondents are of BS degree program.. 
Table 3

Descriptive Information of Nomophobia

\begin{tabular}{lcc}
\hline Nomophobia & Frequency & Percent \\
\hline Non-Nomophobic & 0 & $0 \%$ \\
Mild Nomophobia & 16 & $5.3 \%$ \\
Moderate Nomophobia & 204 & $68.0 \%$ \\
Severe Nomophobia & 80 & $26.7 \%$ \\
\hline \multicolumn{1}{c}{ Total } & 300 & $100.0 \%$ \\
\hline
\end{tabular}

Table 3 displays the frequency distribution of nomophobia and it is expressed in terms of percentage. Frequency table shows (80) $26.67 \%$ respondents show severe nomophobia, (204) 68.0\% respondents show moderate nomophobia, (16) $5.3 \%$ show mild nomophobia where $0 \%$ respondents show no nomophobia.

Table 4

Mean, SD \& t-value of Anxiety at Stage 1, 2, and 3 among Control $(n=150)$ and Experimental Group $(n=150)$

\begin{tabular}{|c|c|c|c|c|c|c|c|}
\hline \multirow[b]{2}{*}{ Conditions } & \multirow[b]{2}{*}{ M } & \multirow[b]{2}{*}{ SD } & \multirow[b]{2}{*}{$t(298)$} & \multirow[b]{2}{*}{$P$} & \multicolumn{2}{|c|}{$95 \% C I$} & Cohen's \\
\hline & & & & & $L L$ & $U L$ & $D$ \\
\hline
\end{tabular}

Stage 1

$\begin{array}{llllllll}\text { I } & 40.15 & 8.35 & 1.25 & 0.213 & -0.68 & 3.02 & 0.14 \\ \text { II } & 38.98 & 7.89 & & & & & \end{array}$

Stage 2

$\begin{array}{llllllll}\text { I } & 48.60 & 7.61 & 23.36 & 0.001 & 14.91 & 17.70 & 2.66 \\ \text { II } & 32.29 & 4.19 & & & & & \end{array}$

Stage 3

$\begin{array}{crrrrrrr}\text { I } & 56.78 & 8.61 & 28.50 & 0.001 & 21.97 & 25.22 & 3.29 \\ \text { II } & 33.18 & 5.36 & \\ \begin{array}{l}\text { Note. } p<0.001^{* * *}, p<0.01^{* *}, p<0.05^{*} . I= \\ \text { condition II. }\end{array}\end{array}$

Table 4 shows group difference of anxiety at stage 1,2, and 3. However, stage 1 contains experimental condition I and experimental condition II. Results show no difference in anxiety at stage 1. The mean and standard deviation (SD) values of 
condition 1 are 40.15 and 8.53 , where the values for condition 2 are 38.98 and 7.89 , respectively. The t-statistic value of group difference in stage 1 is 1.25 , so it clearly shows that there is no significant group difference between two conditions at stage 1 . Results show the mean difference in anxiety at stage 2 . The mean and SD values for condition I are 48.60 and 7.61 where the mean and SD values for condition II are 32.29 and 4.19, respectively. The t-statistic value of group difference in stage 2 is 23.36 so, it clearly shows that there is a significant group difference between both conditions. Results show the mean difference in anxiety at stage 3. The mean and SD value for condition I are 56.78 and 8.61 the mean and SD value for condition II are 33.18 and 5.36, respectively. The t-statistic value of group difference in stage 3 is 28.50 so, it clearly shows that there is a significant group difference between both conditions (see Table 4).

Table 5

M., SD \& t-value of Nomophobia among Experimental Group I (Mobile Phones Taken Away) $(n=150)$ and Experimental Group II (Mobile Phones Switched Off) on Stage 3. $(n=150)$

\begin{tabular}{lcccccccc} 
& & & & & \multicolumn{3}{c}{$95 \% C I$} & Cohen's \\
\cline { 6 - 7 } Conditions & $\mathrm{M}$ & $\mathrm{SD}$ & $t(298)$ & $p$ & $L L$ & $U L$ & $d$ \\
\hline $\mathrm{I}$ & 100.34 & 15.03 & 11.55 & 0.001 & 16.84 & 23.77 & 1.38 \\
$\mathrm{II}$ & 80.03 & 15.44 & & & & & \\
$\begin{array}{l}\text { Note. } p<0.001^{* * *} \\
\text { condition II. }\end{array}$
\end{tabular}

Table 5 exhibits group difference of nomophobia. However, this group contains experimental group I and II. Results show the mean difference between the groups. The mean and SD value of experimental group I are 100.34 and 15.03 where the mean and SD value of experimental group II are 80.03 and 15.44, respectively. The $t$-statistic value of group difference in nomophobia is 11.55 so, it clearly shows that there is a significant nomophobia between both groups. 
Table 6

Comparison of Scores of Anxiety in Experimental Group I and Experimental Group II $(N=150)$

\begin{tabular}{|c|c|c|c|c|c|}
\hline \multirow[t]{3}{*}{ Group } & Stage 1 & Stage 2 & Stage 3 & \multirow[t]{3}{*}{$\mathrm{F}$} & \multirow[t]{3}{*}{$\mathrm{P}$} \\
\hline & $\mathrm{M}(\mathrm{SD})$ & $\mathrm{M}(\mathrm{SD})$ & $\mathrm{M}(\mathrm{SD})$ & & \\
\hline & $\mathrm{N}=150$ & $\mathrm{~N}=150$ & $\mathrm{~N}=150$ & & \\
\hline I & $\begin{array}{l}40.5 \\
(8.35)\end{array}$ & $\begin{array}{l}48.86 \\
(7.60)\end{array}$ & $\begin{array}{l}56.78 \\
(8.61)\end{array}$ & 147.89 & .001 \\
\hline II & $\begin{array}{l}38.92 \\
(7.89)\end{array}$ & $\begin{array}{l}32.29 \\
(4.19)\end{array}$ & $\begin{array}{l}33.18 \\
(5.35)\end{array}$ & 53.74 & .001 \\
\hline
\end{tabular}

Table 6 shows the comparison of Scores of anxiety in experimental conditions I and II condition. Results show the M, SD, F, mean difference among Scores of anxiety, SE and confidence interval. In experimental condition I, mean and SD for stage 1 are 40.5(8.35); for second stage 48.86(7.60); and for the third stage 56.78(8.61) where $F$ is 154.410 which shows significant results. For condition I stage 1 shows the significant difference with stages 2 and 3. Stage 2 shows the significant difference with stage 1 and 3. Finally stage 3 shows the significant difference with stage 1 and 3 respectively. In experimental condition II mean and SD for stage 1 are 38.98(7.89); for second stage $32.29(4.19)$ and for third stage $33.18(5.35)$ where $F$ is 4.026 which shows significant results. For anxiety difference in experimental condition II; stage 1 shows no significant difference with stage 2 where stage 1 shows significant difference with stage 3 respectively. Stage 2 shows no significant difference with stage 1 and stage 3 respectively. Finally, stage 3 shows significant difference with stage 1 where stage 3 shows no difference with stage 2 respectively.

\section{Discussion}

The purpose of this study was to explore how nomophobia is an emerging fear among young generation of today's world. It was aimed to examine if their smart phones are taken away from them then is there any increase in anxiety stage. In this research, anxiety was measured at three stages among smartphone users. Many researches have been conducted on smart phone separation and addiction. In one study researcher checked the cognitive ability of participants when their iPhones were ringing and were not with them. Participants show feelings of unpleasantness and anxiety and physiological responses like increase in heart rate and blood pressure (Clayton, Leshner \& Almond, 2015). 
There were two conditions in this study condition I and condition II. Participants were randomly assigned to groups. Smart phones were taken away from experimental group I whereas group II participants were strictly instructed not to use their phones during the experiment. The first hypothesis was that experimental group I will show high level of anxiety as compared to experimental group II. The results supported the hypotheses of the study. At Stage 1 of anxiety was a baseline, at that point both groups had their smart phones with them. At stage 2 when smart phones were taken away in experimental group I whereas in experimental group II participants were instructed not to use their smart phones then after this manipulation the participants of experimental group I showed huge change in their state anxiety whereas no such changes were observed in experimental group II.

At stage 3 when again check their state anxiety, participants spent almost two hours without their smart phones and a high increase in anxiety feelings was shown by participants in experimental group I whereas no such feelings were shown by participants of experimental group II. The slight change at stage 2 and stage 3 in mean and SD for group II might be due to the confounding variables like task ambiguity, nervousness, whereas difference in anxiety level has been reported in experimental group I. It might possible that these differences are because of less social connection of these participants during study. There is possibility that they were feeling helpless when their smart phones were detached from them and as there was no chance of social communication and interaction. They were nervous as they were unable to contact socially with friends and family, they were thinking if someone would be calling them or texting and they would not be able to get Facebook notifications or mails etc.

Heavy smartphone users often face fear of missing out. A concept which means that individuals feel that they are out of touch with others, if their social connection is lost then they would be unable to get notifications related to some event or miss some event or meeting with friends and due to these reasons, they feel worried, fearful and anxious. (Przybylski, Murayama, DeHaan, \& Gladwell, 2013). FoMO increases the levels of anxiety. Participants during the experiment were coming to researcher and were asking to return their smart phones back. One of the participant was so panic that his class fellows were consoling him not to worry. A study on nomophobia in which the researcher discussed the case report of a patient who suffers from panic disorder and agoraphobia and from the same case study he examined the relationship between panic disorder and nomophobia. The patient was so much dependent on 
his smart phone that he only felt safe with smartphone (King, Valença, \& Nardi, 2010).

\section{Limitations and Suggestions}

Some of the limitations related to this could be STAI used to measure only state response, this inventory does not measure physiological responses like heart rate and blood pressure. Some other measures will be needed in future investigation to measure these responses. Both conditions of study were not administered at the same time. If applied in the same class at the same time, then there would be a possibility that participants of experimental group I show more anxiousness. This research only consisted of university students and only from two departments so there is difficulty in generalizing results. Sample size was small. Limited cooperation of the sample was experienced. For future research purpose, researcher should keep in mind some suggestions in order to do it in a more precise way. Sample size should be large. Data should be collected from colleges and other universities for further studies. Experimental condition I and experimental study II should be applied at the same time in future to get better results.

\section{Conclusion}

It is concluded from the finding of the study that smartphones have become an integral part of the lives of people. In the absence of smartphones one may start feeling of restlessness and anxiety. In this modern world the increasing trend of new technologies have made people so much dependent and addicted to it. The aim of this study was to investigate effect of separation from smartphones on level of anxiety. Experimental group I showed more increase in anxiety as compared to group II because smart phones were taken away from participants of experimental group I.

\section{References}

American Psychiatric Association (2013) Diagnostic and statistical manual of mental disorders (5th ed.). Arlington, VA: American Psychiatric Publishing.

Bragazzi, N., \& Del Puente, G. (2014). A proposal for including nomophobia in the new DSM-V. Psychology research and behavior management. 7. 155-60. 10.2147/PRBM.S41386.

Baillie, D. W. (2011). Sixty eight per cent of us hallucinate. British Medical Journal, 342. 
Bianchi, A., \& Phillips J. G. (2005). Psychological predictors of problem mobile phone use. Cyberpsychology \& Behavior, 8(1), 39-51. 10.1089/cpb.2005.8.39.

Billieux, J., Van der Linden, M., \& Rochat, L. (2008). The role of impulsivity in actual and problematic use of the mobile phone. Applied Cognitive Psychology, 22(9), 1195-1210.

Bragazzi, N. L., \& Puenete G. D. (2014). A proposal for including nomophobia in the new DSM-V. Psychology Research and Behavior Management, 7, 155-160.

Cheever, N., \& Rosen, L., Carrier, M., \& Chavez, A. (2014). Out of sight is not out of mind: The impact of restricting wireless mobile device use on anxiety levels among low, moderate and high users. Computers in Human Behavior. 37. 290-297. 10.1016/j.chb.2014.05.002.

Clayton, R. B., Leshner, G., \& Almond, A. (2015). The extended iSelf: the impact of iPhone separation on cognition, emotion, and physiology. Journal of Comput-Mediat Comm, 20(2), 119-135.

Gidron, D. Y. (2013). Trait Anxiety. In Encyclopedia of Behavioral Medicine (p. 1989). New York: Springer New York. doi:10.1007/978-1-4419-1005-9_1539.

Gökçearslan, Ş., Mumcu, F. K., Haşlaman, T., \& Çevik, Y. D. (2016). Modelling smartphone addiction: The role of smartphone usage, self-regulation, general self-efficacy and cyberloafing in university students. Computers in Human Behavior, 63, 639649. https://doi.org/10.1016/j.chb.2016.05.091

Grös, D. F., Antony, M. M., Simms, L. J., \& McCabe, R. E. (2007). Psychometric properties of the State-Trait Inventory for Cognitive and Somatic Anxiety (STICSA): comparison to the State-Trait Anxiety Inventory (STAI). Psychological assessment, 19(4), 369.

Khan, M. (2008). Adverse effects of excessive mobile phone use. International Journal of Occupational Medicine and Environmental Health, 21(4), 289-293.

King, A. L. S., Valença, A. M., \& Nardi, A. E. (2010). Nomophobia: the mobile phone in panic disorder with agoraphobia: reducing phobias or worsening of dependence? Cognitive and Behavioral Neurology, 23(1), 52-54.

King, A. L. S., Valença, A. M., Silva, A. C., Sancassiani, F., Machado, S., \&Nardi, A. E. (2014). "Nomophobia": Impact of Cell Phone Use Interfering with Symptoms and Emotions of Individuals with Panic Disorder Compared with a Control Group. Clinical practice and epidemiology in mental health: CP \& EMH,10, 28-35. Chicago 
Lin, Y. H., Lin, S. H., Li, P., Huang, W. L., \& Chen, C. Y. (2013). Prevalent hallucinations during medical internships: phantom vibration and ringing syndromes. PloS one, 8(6), e65152.

Oulasvirta, A., Rattenbury, T., Ma, L., \& Raita, E. (2012). Habits make smartphone use more pervasive. Personal and Ubiquitous Computing, 16(1), 105-114.

Przybylski, A. K., Murayama, K., DeHaan, C. R., \& Gladwell, V. (2013). Motivational, emotional, and behavioral correlates of fear of missing out. Computers in Human Behavior, 29(4), 1841-1848.

Ribak, R. (2009). Remote control, umbilical cord and beyond: The mobile phone as a transitional object. British Journal of Developmental Psychology, 27(1), 183-196.

Salehan, M., \& Negahban, A. (2013). Social networking on smartphones: When mobile phones become addictive. Computers in Human Behavior, 29(6), 2632-2639.

Sansone, R. A., \& Sansone, L. A. (2013). Cell phones: the psychosocial risks. Innovations in clinical neuroscience, (1).

Sarason, I. G., \& Sarason, B. R. (1990). Test anxiety. In H. Leitenberg (Ed.), Hand-book of social and evaluative anxiety (pp. 475-496). New York: Plenum Press.

Sharma, P., \& Sharma, N., \& Wavare, R. (2015). Rising concern of nomophobia amongst Indian medical students. International Journal of Research in Medical Sciences. 3. 705. 10.5455/23206012.ijrms20150333.

Spielberger, C. D. (1983). Manual for the State-Trait Anxiety Inventory (STAI). Palo Alto, CA: Consulting Psychologists Press.

Spielberger, C.D., Sydeman, S.J. (1994). State-Trait Anxiety Inventory and State-Trait Anger Expression Inventory. In M.E. Maruish (Ed.), The use of psychological testing for treatment planning and outcome assessment. (pp. 292-321). Hillsdale, NJ: Lawrence Erlbaum Associates.

Spielberger C. Manual for the State-Trait Anxiety Inventory ( rev. ed.). Palo Alto (CA): Consulting Psychologists Press; 1983.

Tanaka, W. \& Terry-Cobo, S. (2008). Cell phone Addiction. Forbes. Retrieved from http://www.forbes.com/2008/06/15/cellphoneaddict-iphone-tech-wireless08 cx_wt0616addict.html

Verma, R. K., Rajiah, K., Cheang, A., \& Barua, A. (2014). Textaphrenia: An emerging silent pandemic. J Psychiatry, 17, 510-511.

Walsh, S. P., White, K. M., \& Young, R. M. (2009). The phone connection: A qualitative exploration of how belongingness and social identification elate to mobile phone use amongst Australian 
youth. Journal of Community and Applied Social Psychology. doi: 10.1002/casp.983.

Yildirim, C. (2014). Exploring the dimensions of nomophobia: Developing and validating a questionnaire using mixed methods research. Graduate Theses and Dissertations. Paper 14005

Zeidner, M., \& Matthews, G. (2010). Anxiety 101. Springer Publishing Company. 